\title{
Sistem Pendukung Keputusan Penentuan Jurusan Kelas X Dengan Metode AHP Pada MAS Muhammadiyah 12 Punggulan
}

\author{
Tumen $^{1 *}$, Zulfi Azhar ${ }^{2}$ \\ 1,2 Program Studi Sistem Informasi ,STMIK Royal Kisaran, Indonesia \\ tumen@gmail.com, ${ }^{2}$ zulfi_azhar@yahoo.co.id
}

\begin{tabular}{|c|c|}
\hline & \multirow{15}{*}{$\begin{array}{l}\text { Abstrak } \\
\text { Sekolah MAS Muhammadiyah12 Punggulan Airjoman dalam menentukan } \\
\text { sistem penentuan jurusan siswa dikelas X masih belum optimal dimana proses } \\
\text { pengolahan data penentuan jurusan masih menggunakan Microsoft Exel } \\
\text { sehingga data hasil nilai akhir siswa belum dijamin cepat, tepat dan akurat. } \\
\text { Belum adanya aplikasi pengolahan data yang terintegrasi untuk mengetahui } \\
\text { hasil penelususran minat siswa kelas X di SMA MAS Muhammadiyah } 12 \\
\text { Punggulan Airjoman sesuai dengan ketentuan yang berlaku dalam penentuan } \\
\text { jurusan untuk setiap siswa. Untuk itu diperlukan sebuah sistem yang bisa } \\
\text { menunjang proses pegolahan data dalam menentukan sistem penentuan } \\
\text { jurusan siswa dikelas X. Dalam penelitian ini menggunakan metode } \\
\text { Analytical Hierarchy Process (AHP). Metode ini diharapkan dapat } \\
\text { mempermudah guru bimbingan konseling dalam melakukan proses } \\
\text { penentuan jurusan kelas X di SMA MAS Muhammadiyah } 12 \text { Punggulan } \\
\text { Airjoman. Metode yang dilakukan penelitian ini dengan pengumpulan data } \\
\text { dari pengisian formulir yang diberikan kepada guru dan staf sebagai responden. } \\
\text { Hasil yang didapatkan pada implementasi penelitian ini adalah dengan } \\
\text { menghasilkan kriteria Jumlah Nilai Raport(C1) dengan alternatif yang terpilih } \\
\text { yaitu, IPA(A1). }\end{array}$} \\
\hline & \\
\hline & \\
\hline & \\
\hline & \\
\hline & \\
\hline & \\
\hline & \\
\hline & \\
\hline Jurusa & \\
\hline$D$ & \\
\hline Techno & \\
\hline is & \\
\hline & \\
\hline & \\
\hline
\end{tabular}

\section{PENDAHULUAN}

Dalam mendukung perkembangan teknologi yang terus berkembang, dimana komputer bukanlah barang baru, melainkan suatu media yang sangat membantu sekaligus dibutuhkan peranannya bagi manusia sebagai penggunanya. Perkembangan teknologi dapat dirasakan dalam kehidupan sehari-hari, begitu juga dalam dunia pendidikan. Dengan perkembangan teknologi informasi yang sangat beraneka ragam, diperlukan peningkatan mutu dan mekanisme pelayanan dibidang pendidikan agar lebih berdaya guna. Dengan pekembangan ini sarana dan prasarana dunia pendidikan pun harus mengikutinya.

Seiring dengan perkembangan dunia pendidikan yang semakin pesat sekarang ini, penyampaian suatu informasi dari satu pihak ke pihak yang lain juga semakin berkembang dengan luas, khususnya dalam hal kecepatan, keamanan, kemudahan, dan praktis. Salah satu dalam media yang perkembanganya paling pesat sekarang ini yaitu internet. Munculnya media internet akan sangat memudahkan dalam pembelajaran sesuatu yang baru, karena dengan mengakses segala informasi yang ada di internet akan menambah pengetahuan kita. Pencarian-pencarian informasi dapat dilakukan melalui media pencarian search engine yang akan lebih mudah mendapatkan informasi yang kita inginkan.

Sekolah Madrasah Aliyah Swasta (MAS) Muhammadiyah12 Punggulan Airjoman mempunyai banyak siswa, dimana untuk mendapatkan jurusan kepada siswa harus disesuaikan dengan beberapa kriteria dalam menentukan penjurusan di kelas. Dalam menentukan sistem penentuan jurusan siswa dikelas X masih menggunakan Microsoft Excel sehingga data hasil nilai akhir siswa harus menggunakan data yang ada dan dilakukan secara manual dalam menentukan penjurusan pada siswa. Pelaksanaan dalam menentukan penjurusan pada siswa ini belum optimal dan belum adanya aplikasi pengolahan data yang terintegrasi untuk mengetahui hasil penelususran minat siswa kelas X di SMA MAS Muhammadiyah 12 Punggulan Airjoman sesuai dengan ketentuan yang berlaku dalam penentuan jurusan untuk setiap siswa. Dalam penentuan jurusan dilakukan dengan mempertimbangkan beberapa kriteria yaitu jumlah nilai raport, nilai tes penjurusan, minat dan bakat untuk menghasilkan pilihan jurusan yaitu IPA, IPS dan Bahasa. Untuk itu diperlukan sebuah sistem yang bisa menunjang proses pegolahan data dalam menentukan sistem penentuan jurusan siswa dikelas $\mathrm{X}$ dan bisa mempermudah bagian pengelola data penentuan jurusan kelas X SMA MAS Muhammadiyah 12 Punggulan Airjoman secara akurat dan efisien. 


\section{STUDI LITERATUR}

Sekolah adalah sebuah lembaga yang dirancang untuk pengajaran siswa atau murid di bawah pengawasan guru. Sebagian besar negara memiliki sistem pendidikan formal, yang umumnya wajib. Di Indonesia sendiri sekolah dibagi beberapa tingkatan yaitu Sekolah Dasar, Sekolah Lanjutan Tingkat Pertama dan Sekolah Lanjutan Tingkat Atas. Pada Sekolah Lanjutan Tingkat Atas memiliki penjurusan setiap peserta didik yang akan mulai memasuku kelas X (sepuluh). Pada SMAN 1 Kandat penjurusan terbagi menjadi dua yaitu penjurusan untuk program IPA dan IPS(Anon n.d.). Penjurusan tersebut akan disesuaikan dengan kemampuan dan minat siswa bersangkutan. Penjurusan ini memiliki tujuan agar kelak di kemudian hari, pelajaran yang akan diberikan kepada siswa menjadi lebih terarah karena sesuai dengan kemampuan dan minatnya(Agil Putranto, Salamah, and , 2016).

Penempatan siswa sesuai dengan kapasitas kemampuannya atau sering disebut dengan penjurusan siswa di sekolah menengah ditentukan oleh kemampuan akademik yang didukung oleh faktor minat, karena karakteristik suatu ilmu menuntut karakteristik yang sama dari yang dipelajarinya. Dengan demikian, siswa yang mempelajari suatu ilmu yang sesuai dengan karakteristik kepribadiannya akan merasa senang ketika mempelajari ilmu tersebut. Minat dapat mempengaruhi kualitas pencapaian hasil belajar siswa dalam bidang studi tertentu(Zuleha 2020).

Penjurusan di sekolah sudah dimulai di bangku SMA. Siswa sering mengalami kebingungan dalam menentukan jurusan yang akan diambil. Aspek emosional ikut berperan dalam mempertimbangkan jurusan yang akan dipilih, diantaranya karena mengikuti teman, tuntutan orang tua, keterbatasan pengetahuan terhadap jurusan tersebut dan lain sebagainya. Pemikiran lain yang sering muncul dalam menentukan pilihan jurusan adalah siswa atau orang tua sering menganggap bahwa jurusan IPA menjadi pilihan yang lebih baik(Sulystiyawati and Purwaningsih 2017).

Dalam membantu pengambilan keputusan dari sejumlah pilihan diperlukan sistem, memberikan solusi akhir pilihan yang terbaik. Sistem Pendukung Keputusan (SPK) bagian dari Artifical Intelligence yang digunakan untuk memberikan jawaban dari proses perhitungan dari sejumlah pilihan dengan tujuan tertentu. Manfaat SPK memperluas, membantu, menghasilkan solusi stimulan bagi pengambil keputusan dalam memahami persoalannya dengan menyajikan berbagai alternatif pemecahan. Pengambilan keputusan dalam pembuat keputusan manajemen dari masalah semi terstruktur(Na'am 2017). Penggunaan AHP memerlukan sejumlah kriteria yang dicari berdasarkan tujuannya. Sejumlah alternatif adalah pilhan yang akan ditentukan melalui proses perhitungan(Andrade et al. 2015)(Septiani and Siahaan 2017)(Umar, Fadlil, and Yuminah 2018). Sistem pada AHP lebih sederhana dan efektif dalam penggunaan pengambilan hasil yang terbaik. Pengetahuan yang terinci dalam menyusun realitas yang kompleks kedalam bagian elemen pokok, kemudian dibagi kedalam bagian-bagiannya lagi, secara hierarki(Azhar, Jama, and Effendi 2021)(Komsiyah 2014)(Wahyu, Safriadi, and Pratiwi 2017)(Azhar, Effendi, and Muskhir 2021)(Frieyadie and Ramadhan 2018)(Mardiyati, Juliana, and Driyani 2016)(Mary 2014)(Hasugian et al. 2018)

Dalam metode ini diperlukan beberapa kriteria dan beberapa alternatif sebagai pilihan yang ditentukan melalui proses perhitungan(Andika n.d.). Cara ini lebih mudah dan efektif untuk menghasilkan yang terbaik. menjadikan bagian-bagian hierarki dan bertahap(model pembelajaran)

\section{Metode Analytical Hierarchy Process (AHP)}

Langkah dalam metode AHP yaitu :

a. Mendefinisi permasalahan yang terjadi dengan memberikan pembagian secara hierarki secara tersusun.

b. Menentukan prioritas menggunakan pasangan matriks.

c. Sintesis dengan memperbandingkan secara matriks dalam mendapatkan hasil nilai yang prioritas.

d. Mengukur hasil konsistensi

Hasil ukuran konsistensi berdasarkan rumus yang yang telah ditentukan yang dibuatkan dalam tabel.

e. Mengukur hasil nilai Consistency Index, yaitu :

$$
\mathrm{CI}=\frac{[\lambda \max -n]}{\mathrm{n}-1}
$$

$\mathrm{n}=$ banyak jumlah elemen

$\lambda$ maks $=$ angka eigen maksimum dari matriks perbandingan yang berpasangan

f. Menghasilkan nilai Rasio Konsistensi

yaitu :

$$
\begin{aligned}
& \mathrm{CR}=\frac{C I}{R I} \\
& \text { yaitu } \\
& \mathrm{CR}=\text { Rasio Consistency, } \\
& \mathrm{CI}=\text { Indeks Consistency, } \\
& \mathrm{RI}=\text { Indeks secara Random }
\end{aligned}
$$

g. Hasil nilai konsistensi secara hirarki. 
Penilain konsistensi secara hirarki jika nilai perhitungan itu sebagai hasil bernilai benar.

$\mathrm{CR}<0,1$

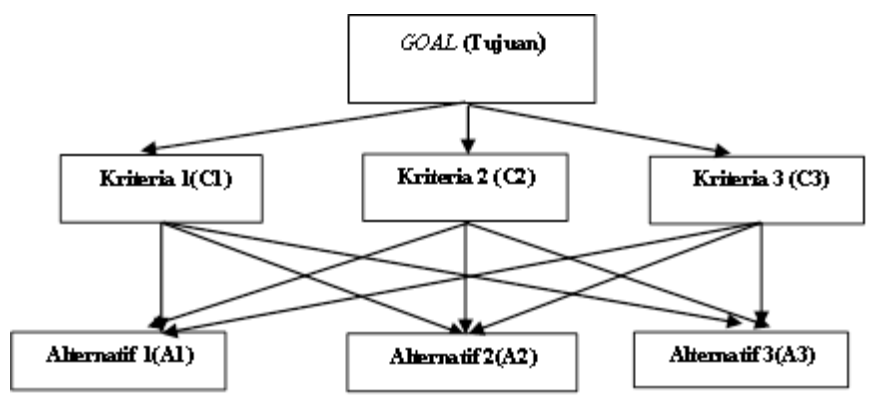

Gambar 1. Bagan Hierarki Pada Metode AHP

METODE

Langkah-langkah yang digunakan pada metode ini yaitu:

a. Langkah 1 Pengumpulan Dokumen Data

Mengumpulkan data di lapangan dengan memilih sejumlah kriteria dan alternatif menggunakan pengisian formulir oleh 40 orang guru dan staf. Para guru dan staf diminta untuk membandingkan kriteria yang dibutuhkan dengan data tersebut yang akan diolah untuk dianalisis.

b. Langkah 2 Penganalisaan Data

Penganalisaan data dengan sejumlah kriteria dan alternatif yang dipilih sesuai tujuan yang direncanakan.

c. Langkah 3 Penggunaan proses uji pada Sistem.

Penggunaan matriks excel, untuk pengujian perhitungan pada sistem.

a. Penggunaan Pemilihan Kriteria

\section{HASIL}

Kriteria yang akan dipilih adalah: Jumlah Nilai Raport(C1), Nilai Tes Penjurusan(C2) dan Minat dan Bakat (C3). Hasil nilai indeks konsistensi pada kriteria perhitungan menjadi konsistensi jika nilai rasio konsistensi hierarkis $(\mathrm{CR})<0,1$. Hasil nilai maksimum adalah jumlah perkalian dalam kolom matriks synthes pada kriteria di tabel 1 dan tabel 2.

Tabel 1

Hasil Hitung Untuk Kriteria

\begin{tabular}{cccc}
\hline \hline Kriteria $(\mathrm{Crt})$ & $(\mathrm{C} 1)$ & $(\mathrm{C} 2)$ & $(\mathrm{C} 3)$ \\
\hline$(\mathrm{C} 1)$ & 1 & 3 & 5 \\
$(\mathrm{C} 2)$ & 0,333 & 1 & 3 \\
$(\mathrm{C} 3)$ & 0,2 & 0,333 & 1 \\
Jumlah & 1,533 & 4,333 & 9 \\
\hline
\end{tabular}

Tabel 2

Normalisasi Kriteria dan Perangkingan

\begin{tabular}{ccccccc}
\hline \hline $\begin{array}{c}\text { Kriteria } \\
(\mathrm{Crt})\end{array}$ & $\mathrm{C} 1$ & $\mathrm{C} 2$ & $\mathrm{C} 3$ & Jumlah & Prioritas & Rangking \\
\hline C1 & 0,652 & 0,692 & 0,556 & 1,900 & 0,633 & 1 \\
$\mathrm{C} 2$ & 0,217 & 0,231 & 0,333 & 0,781 & 0,260 & 2 \\
C3 & 0,130 & 0,077 & 0,111 & 0,318 & 0,106 & 3 \\
Jumlah & 1 & 1 & 1 & 3 & & \\
\hline
\end{tabular}

Tabel 3

Random Indeks

\begin{tabular}{ccccccccccccccc}
\hline \hline $\mathrm{n}$ & 1,2 & 3 & 4 & 5 & 6 & 7 & 8 & 9 & 10 & 11 & 12 & 13 & 14 & 15 \\
\hline $\mathrm{RI}$ & 0 & 0,58 & 0,90 & 1,12 & 1,24 & 1,32 & 1,41 & 1,45 & 1,49 & 1,51 & 1,48 & 1,56 & 1,57 & 1,59 \\
\hline
\end{tabular}

$\lambda \operatorname{maks}=(1,533 * 0,633)+(4,333 * 0,260)+(9 * 0,106)$

$\lambda$ maks $=3,0554$ 
$C I=\frac{3,055361493-3}{(3-1)} \quad \mathrm{CI}=0,027680747$

Penentuan angka $\mathrm{RI}=0,58$ dari tabel dengan nilai $\mathrm{n}=3$.

$C R=\frac{0,027680747}{0,58}=0,047725$

Perhitungan nilai $\mathrm{CR}=0,047725$ memenuhi syarat, $\mathrm{CR}<0,1$ dinyatakan konsisten/benar.

b. Penggunaan Pemilihan Alternatif

Pemilihan Alternatif (A) dalam menentukan jurusan siswa dikelas X adalah: IPA(A1), IPS(A2) dan Bahasa(A3).

Tabel 4

Hasil Hitung Pada Alternatif

\begin{tabular}{cccc}
\hline \hline Alternatif $(\mathrm{A})$ & $(\mathrm{A} 1)$ & $(\mathrm{A} 2)$ & $(\mathrm{A} 3)$ \\
\hline (A1) & 1 & 3 & 5 \\
(A2) & 0,333 & 1 & 3 \\
(A3) & 0,2 & 0,333 & 1 \\
Jumlah & 1,533 & 4,333 & 9 \\
\hline
\end{tabular}

Tabel 5

Normalisasi Alternatif dan Perangkingan

\begin{tabular}{ccccccc}
\hline \hline Alternatif $(\mathrm{A})$ & (A1) & $(\mathrm{A} 2)$ & $(\mathrm{A} 3)$ & Jumlah & Prioritas & Rangking \\
\hline (A1) & 0,652 & 0,692 & 0,556 & 1,900 & 0,633 & 1 \\
(A2) & 0,217 & 0,231 & 0,333 & 0,781 & 0,260 & 2 \\
(A3) & 0,130 & 0,077 & 0,111 & 0,318 & 0,106 & 3 \\
Jumlah & 1 & 1 & 1 & 3 & & \\
\hline
\end{tabular}

Penilaian indeks konsistensi pada alternatif adalah :

$\lambda$ maks $=(1,533 * 0,633)+(4,333 * 0,260)+(9 * 0,106)$

$\lambda$ maks $=3,055361493$

$C I=\frac{3,055361493-3}{(3-1)} \quad \mathrm{CI}=0,027680747$

Menentukan nilai $\mathrm{RI}=0,58$ dari tabel dengan nilai $\mathrm{n}=3$.

$C R=\frac{0,027680747}{0,58} \quad \mathrm{CR}=0,047725425$, bersifat konsisten dimana $\mathrm{CR}<0,1$.

\section{PEMBAHASAN}

Metode Analytical Hierarchy Process(AHP) yang digunakan ini dalam pemilihan menentukan jurusan di Kelas X dapat menghasilkan kriteria dan alternatif yang prioritas secara perangkingan. Metode ini dapat memberikan suatu keputusan dengan menentukan terlebih dahulu beberapa kriteria dan alternatif dalam memberikan solusi penyelesaian.

\section{KESIMPULAN}

Hasil akhir ini dari penelitian ini bahwa menggunakan metode AHP dapat menghasilkan pemilihan dalam menentukan jurusan siswa dikelas $\mathrm{X}$ dengan beberapa kriteria pemilihan yang berpengaruh dan juga alternatif-alternatif yang terpilih. Nilai perangkingan yang diperoleh dari alternatif dengan nilai berurutan adalah IPA(A1), IPS(A2) dan Bahasa(A3).

\section{REFERENSI}

Agil Putranto, Erfan, Umi Salamah, and, Wiharto. 2016. "Sistem Pendukung Keputusan Penjurusan Siswa Kelas X SMA Negeri 2 Dengan Metode Fuzzy C-Means Dengan Penggunaan Daya Dukung Minat.” Jurnal Teknologi \& Informasi ITSmart 1(2):68.

Andika, Rheza. n.d. "Analytic Hierarchy Process (AHP) Dan Perhitungan Contoh Kasus AHP."

Andrade, André, João De Deus, Rodrigues Gois, and Paulo Roberto. 2015. "Proposal for Using 
AHP Method to Evaluate the Quality of Services Provided by Outsourced Companies." Procedia - Procedia Computer Science 55(Itqm):715-24.

Anon. n.d. "8_aris.Pdf."

Azhar, Zulfi, Hansi Effendi, and Mukhlidi Muskhir. 2021. "Decision Support System Analytical Hierarchy Process in Learning Method Selection Decision Support System Analytical Hierarchy Process in Learning Method Selection."

Azhar, Zulfi, Jalius Jama, and Hansi Effendi. 2021. "The Analytical Hierarchy Process of Decision Support Systems in Choosing Learning Models." 12(10):2278-85.

Frieyadie, Frieyadie, and Surya Mahendra Ramadhan. 2018. "Penerapan Metode AHP Untuk Membantu Siswa Memilih Jurusan Yang Tepat Di SMK.” Jurnal RESTI (Rekayasa Sistem Dan Teknologi Informasi) 2(3):662-67.

Hasugian, Abdul Halim, Hendra Cipta, Prodi Ilmu Komputer, and Prodi Matematika. 2018. "Analisa Dan Perancangan Sistem Pendukung Keputusan Pemilihan Pasangan Hidup Menurut Budaya Karo Dengan Menggunakan Metode Analitycal Hierarchy Process ( AHP ) Abstrak." 6341(April):14-30.

Komsiyah, Siti. 2014. "Aplikasi Analytical Hierarchy Process (AHP) Pada Pemilihan Software Manajemen Proyek." ComTech: Computer, Mathematics and Engineering Applications $5(2): 870$.

MARDIYATI, SRI, JULIANA, and DEWI DRIYANI. 2016. "Sistem Penunjang Keputusan Pemilihan Perumahan Dengan Metode AHP." Faktor Exacta 8(2):63-71.

Mary, Thomson. 2014. "Sistem Pendukung Keputusan Menggunakan Metode Analytic Hierarchy Process ( AHP ) Pemilihan Metode Pembelajaran Untuk Mata Kuliah Praktikum Yang Berbasiskan Bahasa Pemrograman Komputer Jurnal Edik Informatika." 1:23-29.

$\mathrm{Na}$ 'am, Jufriadif. 2017. "Sebuah Tinjauan Penggunaan Metode Analythic Hierarchy Process (AHP) Dalam Sistem Penunjang Keputusan (SPK) Pada Jurnal Berbahasa Indonesia." Jurnal Mediasisfo 11(1978-8126):888-95.

Septiani, Dian, and Fernando B. Siahaan. 2017. "KARYAWAN BERPRESTASI DENGAN METODE ANALITICAL HIERARCHY PROCESS ( AHP ) PADA PT . ICHIYA INDONESIA." III(1):1-8.

Sulystiyawati, Esthi Wiji, and Indriyati Eko Purwaningsih. 2017. "Peran Hasil Tes Penjurusan Studi Terhadap Pemilihan Jurusan Pada Siswa Sma.” Jurnal Spirits 5(1):35.

Umar, Rusydi, Abdul Fadlil, and Yuminah Yuminah. 2018. "Sistem Pendukung Keputusan Dengan Metode AHP Untuk Penilaian Kompetensi Soft Skill Karyawan.” Khazanah Informatika: Jurnal Ilmu Komputer Dan Informatika.

Wahyu, Abang M. Zaid, Novi Safriadi, and Helen Sasty Pratiwi. 2017. "Sistem Pendukung Keputusan Pemilihan Mata Kuliah Pilihan Menggunakan Metode Analytic Hierarchy Process ( Studi Kasus : Jurusan Teknik Elektro Fakultas Teknik Universitas Tanjungpur A ).” Jurnal Sistem Dan Teknologi Informasi (JUSTIN) 5(2):160-63.

Zuleha. 2020. "Penentuan Jurusan Sekolah Menengah Atas Menggunakan Metode K-Nearest Neighbor Classifier Pada Sman 2 Singingi.” Jurnal Perencanaan, Sains, Teknologi, Dan Komputer 3(1):199-206. 
Digital Transformation Technology (Digitech) | e-ISSN : 2807-9000

Volume 1, Number 2, Sep 2021 
